\title{
Unilateral Bipedicled Subcostal and Lumbar Arteries Perforator Flap for Reconstruction of Large Myelomeningocele Defects
}

\author{
MAHFOUZ SHEHATA, M.D., M.R.C.S. and MOHAMED A. WAHSH, M.D. \\ The Department of General Surgery, Plastic Surgery Unit, Faculty of Medicine, Zagazig University, Egypt
}

\begin{abstract}
Background: A plenty of options have been described for reconstruction of large myelomeningocele defects. We reported our experience of using bipedicled subcostal and lumbar arteries perforator flap.

Material and Methods: During a period of 31 months 23 neonates with large myelomeningocele defects were reconstructed with unilateral bipedicled subcostal and lumbar artery perforator flaps. We did not report any total flap loss.

Results: Only one flap suffered distal necrosis that becomes well after debridement and re-suturing. All donor sites were closed primary.

Conclusion: Our study confirmed reliability of bipedicled subcostal and lumbar artery perforator flaps in reconstruction of large myelomeningocle defects.
\end{abstract}

Key Words: Myelomeningocele - Bipedicled - PerforatorSubcostal - Iumbar.

\section{INTRODUCTION}

There are plenty of methods tried for closure of large myelomeningocele defects. Ranging from skin grafting, local flaps, muscle flaps, musculocutaneous flaps, perforator flaps to free flaps [1].

In this study we presented a 3 years' experience in the repair of large myelomeningocele lumber and lumbosacral defects utilizing bipedicled subcostal and lumber artery perforator flaps.

Subcostal arterery perforator flaps were first described by Feinendegen and Klos, 2002 [2] for reconstruction of lumber defects. Its perforator emerges at the lateral edge of latissimus dorsi muscle just below the last rib and extends forward toward the rectus sheath [3].

The lumbar artery perforators first reported by Kroll and Rosenfield, 1988 [4] while it's anatomical bases has been described by Lui et al., 2009 [5]. The perforators exit the abdominal wall just lateral to erector spinae muscles [6].

\section{PATIENTS AND METHODS}

All reconstructions performed from December 2014 to June 2017. Patient's demographics, physical examination findings, defects sizes, flap sizes and postoperative complications were reported in Table (1).

Over 31 months a unilateral bi-pedicle sub costal and lumber artery perforator flap was used to reconstruct large myelomeningocele defect. Patients included 13 male and 10 females ranging in age from one to 3 weeks. They all had large myelomeningocele defects.

\section{Operative technique:}

A flap marking with its size determined by the myelomeningocele defect is made over the patients back after determination of subcostal and upper lumber perforators using Doppler.

The flap margins are outlined obliquely just below the last rib and few centimeters above the iliac crest with the distal limit at lateral edge or over the rectus muscle.

The proximal limit is the lateral border of erector spinae muscle. The width of the flap is designed so that it can cover the defect without any tension.

All surgeries performed under general anesthesia. The flap is raised from distal to proximal and from upward downward. Care taken to be subfascial until the lateral edge of latissimus then continue submuscular till the lateral edge of erector spinae muscle. After complete rising of the flap it is transferred to the defect and the donor site is primary closed. (Figs. 1-7). 


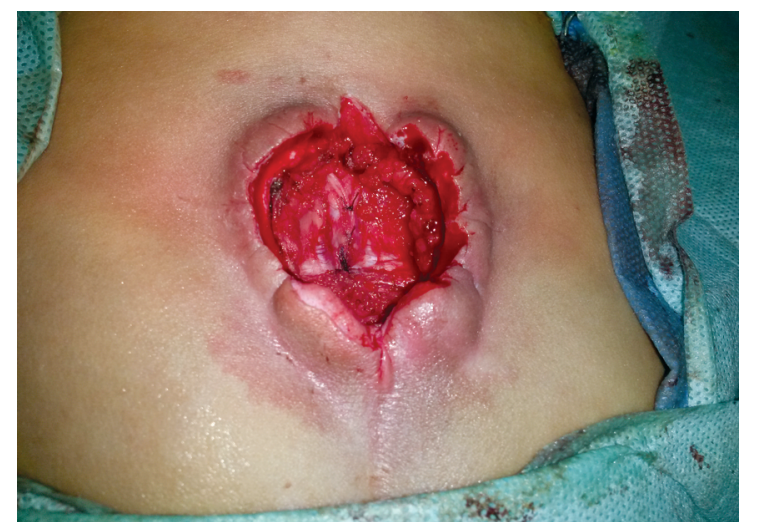

Fig. (1): Case 6 a large defect after closure of the dura by neurosurgeon.

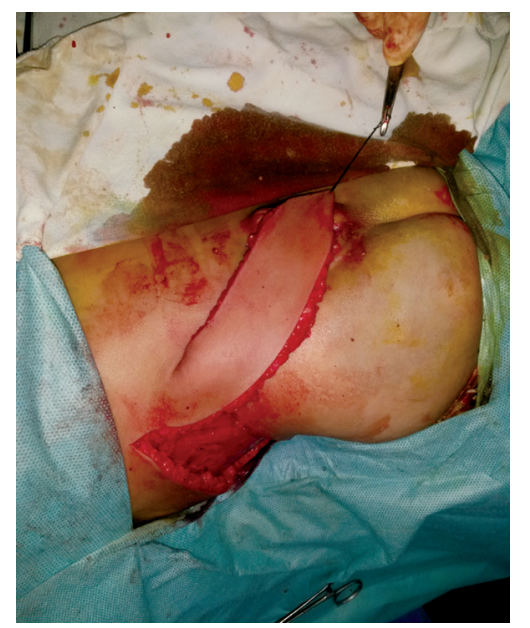

Fig. (3): Case 6 the flap easily reaches the defect.

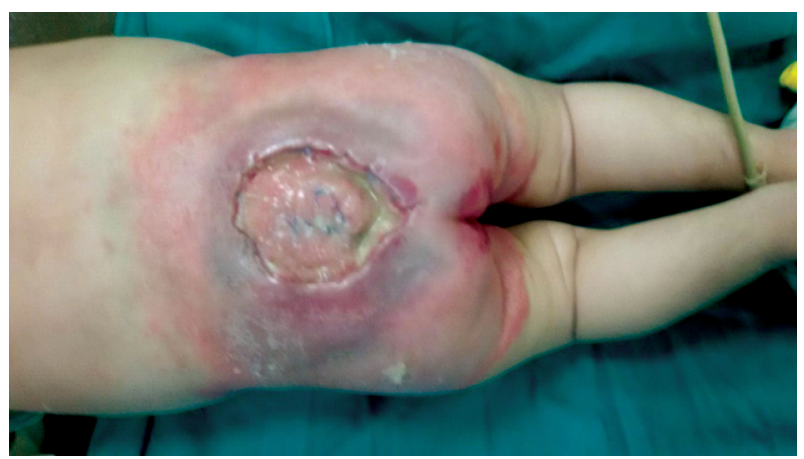

Fig. (5): Case 10 defect after closure of the dura by neurosurgeon.

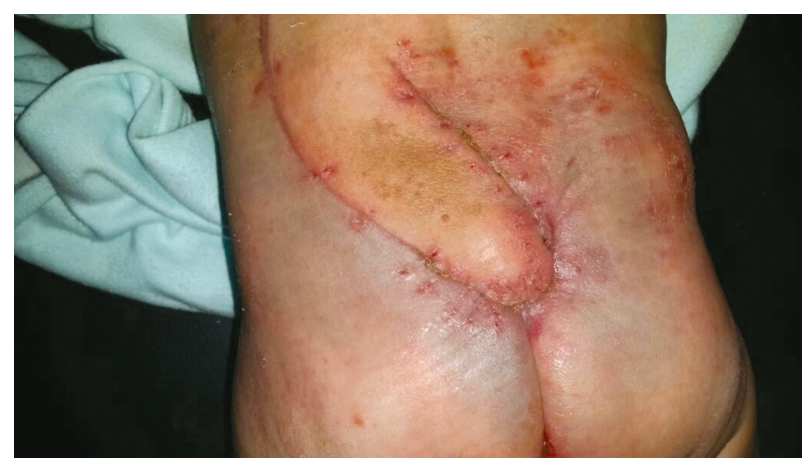

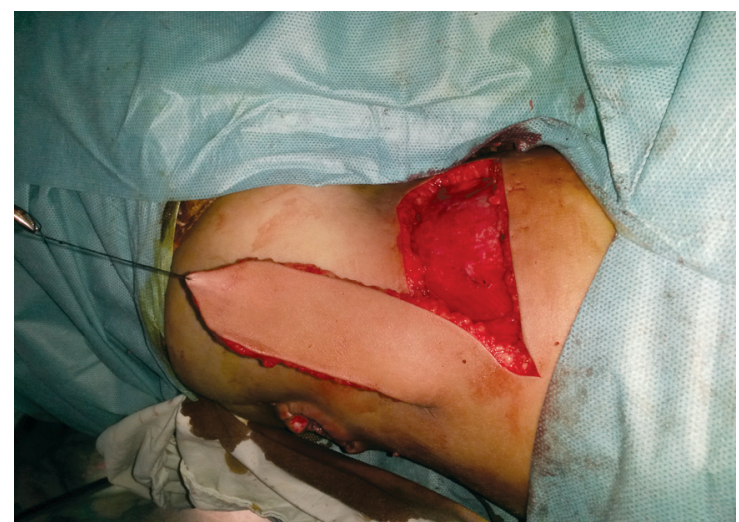

Fig. (2): Case 6 the flap raised and shown part of latissimus within the flap.

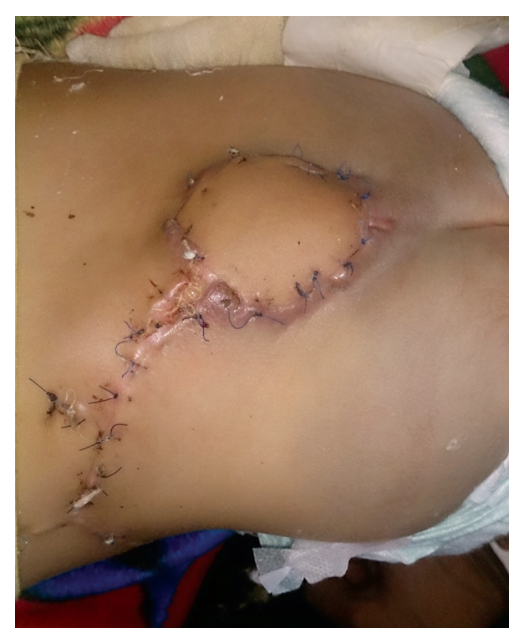

Fig. (4): Case 6 the defect closed and the donor closed primary.

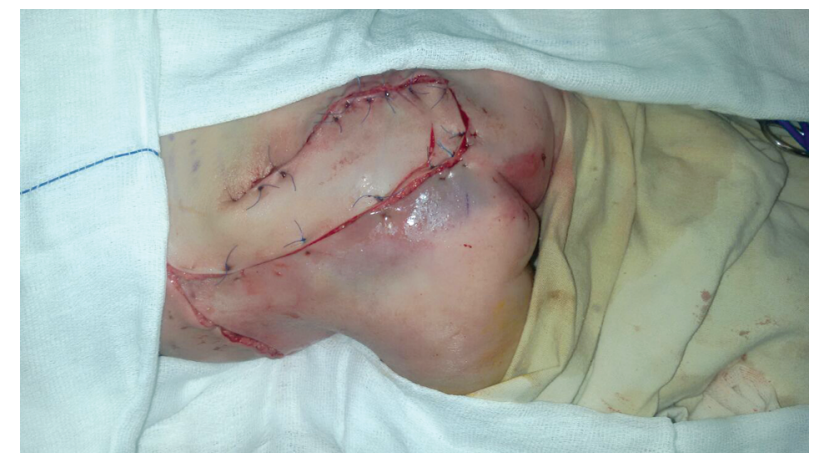

Fig. (6): Case 10 postoperative after flap insetting.

Fig. (7): Case 10 late postoperative show complete closure of the defect. 


\section{RESULTS}

An average follows-up period was 6 months with a range from 0 to 29 months. The flap sizes ranged from $6 \times 13 \mathrm{~cm}$ to $10 \mathrm{x} 18 \mathrm{~cm}$ and all survived without any total loss. The donor sites healed satisfactorily.

Early and late complications were not seen apart from one case of distal flap necrosis. Debridement and re-suturing was performed after that the flap showed reliable closure of the defect.

Table (1): Documentations of patients.

\begin{tabular}{|c|c|c|c|c|c|c|}
\hline $\begin{array}{l}\text { Pt. } \\
\text { no. }\end{array}$ & Sex & Age & $\begin{array}{c}\text { Defect size } \\
(\mathrm{CM})\end{array}$ & $\begin{array}{c}\text { Flap size } \\
\text { CM) }\end{array}$ & Region & Complication \\
\hline 1 & M & 14 & $8 \times 10$ & $9 \times 16$ & Lumbosacral & None \\
\hline 2 & M & 7 & $8 \times 9$ & $8.5 \times 16$ & Lumbosacral & None \\
\hline 3 & $\mathrm{~F}$ & 9 & $8 \times 10$ & $9 \times 18$ & Lumbosacral & None \\
\hline 4 & $\mathrm{~F}$ & 8 & $6 \times 10$ & $9 X 17$ & Lumbosacral & None \\
\hline 5 & $\mathrm{~F}$ & 12 & $8 X 11$ & $10 \times 19$ & Lumbosacral & None \\
\hline 6 & M & 10 & $6 \times 8$ & $7 X 16$ & Lumbosacral & None \\
\hline 7 & M & 7 & $7 X 6$ & $6.5 \times 14$ & Lumbosacral & None \\
\hline 8 & $\mathrm{~F}$ & 14 & $5 \times 7$ & $6.5 \times 13$ & Lumbar & None \\
\hline 9 & M & 12 & $8 \times 5$ & $7 X 15$ & Lumbosacral & None \\
\hline 10 & M & 8 & $7 \times 5$ & $6.5 \times 13$ & Lumbar & None \\
\hline 11 & M & 11 & $5 \times 6$ & $5.5 \times 12$ & Lumbar & None \\
\hline 12 & $\mathrm{~F}$ & 10 & $9 \times 9$ & $8 \times 15$ & Lumbosacral & None \\
\hline 13 & $\mathrm{~F}$ & 12 & $8 \times 5$ & $7.5 \times 14$ & Lumbar & None \\
\hline 14 & $\mathrm{~F}$ & 7 & $9 \times 6$ & $8.8 \times 18$ & Lumbosacral & $\begin{array}{l}\text { Distal } \\
\text { necrosis }\end{array}$ \\
\hline 15 & M & 8 & $7 X 4$ & $6.5 \times 14$ & Lumbosacral & Noe \\
\hline 16 & M & 13 & $8 X 4$ & $7 X 15$ & Lumbosacral & None \\
\hline 17 & M & 14 & $8 \times 6$ & $7.5 \times 14$ & Lumbar & None \\
\hline 18 & $\mathrm{~F}$ & 10 & $6 \times 6$ & $6 \times 12$ & Lumbar & None \\
\hline 19 & M & 8 & $9 \times 4$ & $8.5 \times 15$ & Lumbosacral & None \\
\hline 20 & $\mathrm{~F}$ & 8 & $9 \times 5$ & $8 X 14$ & Lumbosacral & None \\
\hline 21 & $\mathrm{~F}$ & 7 & $7 \times 6$ & $6.5 \times 13$ & Lumbar & None \\
\hline 22 & M & 9 & $8.5 \times 5$ & $8 X 14$ & Lumbar & None \\
\hline 23 & M & 13 & $10 \times 6$ & $9.5 \times 19$ & lumbosacral & None \\
\hline
\end{tabular}

\section{DISCUSSION}

Several reconstructive methods have been described for closure of large myelomeningocele defects. These methods including skin grafting [7], tissue expansion [8], limberg rhomboid flap [9] bipedicle flaps [10], biloped flaps [9] bilateral v-y advancement [11] Z-plasty [12] and bilateral latissimus dorsi flaps [1].

The disadvantages of skin graft is that it could not provide sufficient soft tissue cover for the neural tissues beside the risk of ulceration and recurrent gibbus [13]. Disadvantages of random pattern flaps are distal flap necrosis, the need for extensive undermining and suture line over the repair [12]. The disadvantage of muscle and/or musculoculocutaneous flaps are increased blood loss, long operating time and disruption of the muscles carry potential risk of functional loss in a potentially paraplegic wheel chair patient [14].
Knowledge of vascular anatomy and skin territories supplied by arteries is essential for perforator flap surgery $[\mathbf{4 , 1 5}]$.

The use of perforator flaps including the lumbar, superior gluteal and the dorsal intercostal arteries has also been previously described [9].

Although each flap alone is valuable option however it seems to be useful only for small to medium sized defects $[\mathbf{2 , 1 2}]$.

Also, the use of bilateral perforator flaps have multiple drawbacks of additional donor site problems, requirement for skin grafting and ugly scars of skin grafting on long term $[\mathbf{1 6 , 1 8}]$.

In this study we offered a unilateral flap utilizing two perforators of the subcostal and the lumbar arteries. The lumbar arteries are 4 in numbers and the perforators of the $1^{\text {st }}, 2^{\text {nd }}$ and $4^{\text {th }}$ reported to be the most constant $[\mathbf{5 , 6 , 9 ]}$.

The perforators of the lumbar vessels exiting at $5-8 \mathrm{~cm}$ from the posterior midline at the lateral boder of erictor spinae muscle and extend towards the anterior superior iliac spine and rectus muscles $[9,19]$.

Subcostal perforator flaps depend on subcostal artery perforator not widely reported in literature but it has constant anatomical location within $5 \mathrm{~cm}$ from the spinous process then passes below the last rib within the latissimus dorsi before exiting to the subcutaneous tissues at its lateral border $[3,11]$. The usages of double perforators have been reported in literatures $[\mathbf{5 , 1 1 , 2 0 ]}$. Keles et al., 2014 [21] reported that double perforator flaps supply satisfactory larger dimensions than single pedicle one.

We confirmed this in our study as the flap with these two perforators provides a well vascularized and durable coverage. It does not cause any functional deficit or sacrificing of any of back muscles.

Instead of including small piece of latissimus dorsi muscle to give wide mobility and to increase the flap length, it does not lead to any functional disability as was reported in a study done by Sarifakioglu, et al., 2003 [1].

\section{Conclusion:}

Bipedicled perforator flap utilizing both subcostal and lumbar arteries perforators will provide reliable, durable coverage of large mylomeningocele without a need for morbidities. So, it is a valuable option in reconstruction of large myelomeningocele defects. 


\section{REFERENCES}

1- Sarifakioglu N., Bingu L.F., Terzioglu A., et al.: Bilateral split latissimus dorsi V-Y flaps for closure of large thoracolumbar meningomyelocele defects. Br. J. Plast. Surg., 5: 303Y306, 2003.

2- Feinendegen D.L. and Klos D. A.: Subcostal artery perforator flap for a lumbar defect. Plast. Reconstr. Surg., 109: 2446, 2002.

3- Feinendegen D.L., User T.N., Herrmann G., Abderhalden S., Gelin E.V., Banic A. and Constantinescu M.A.: The subcostal artery perforator flap; an anatomical study. Journal of Plast. Reconstr. Aesthetic. Surg., 61: 14961502,2008

4- Kroll S.S. and Rosenfield L.: Perforator-based flaps for low posterior midline defects. Plast. Reconstr. Surg., 81: 561-566, 1988.

5- Lui K.W., Hu S., Ahmad N. and Tang M.: Threedimensional angiography of the superior gluteal artery and lumbar artery perforator flap. Plast. Reconstr. Surg., 123: 79-86, 2009.

6- Kato H., Hasegawa M., Takada T. and Torii S.: The lumbar artery perforator based island flap: Anatomical study and case reports. Br. J. Plast. Surg., 52: 541-546, 1999.

7- Luce E.A., Stigers S.W., Vandenbrink K.D. and Walsh J.W.: Split-thickness skin grafting of the myelomeningocele defect: A subset at risk for late ulceration. Plast. Reconstr. Surg., 87 (1): 116-121, 1991

8- Kesan K., Kothari P., Gupta R., Gupta A., Karkera P., Ranjan R., Mutkhedkar K. and Sandlas G.: Closure of Large Meningomyelocele Wound Defects with Subcutaneous Based Pedicle Flap with Bilateral V-Y Advancement: Our Experience and Review of Literature. Euro. J. Pediatr. Surg., 2014.

9- Shim J.H., Yoon E.S., Kim D.W. and Kim S.D.: Closure of myelomeningocele defects using a limberg flap or direct repir. Arch. Plast. Surg., 43: 26-31, 2016

10- Mangels K.J., Tulipan N., Bruner J.P., et al.: Use of bipedicular advancement flaps for intrauterine closure of myeloschisis. Pediatr. Neurosurg., 32: 52-6, 2000.
11- Basterzi Y. and Tenekeci G.: Dorsal Intercostal Artery Perforator Propeller Flaps: A Reliable Option in Reconstruction of Large Meningomyelocele Defects. Annal. Plast. Surg., 76 (4): 434-437, 2016.

12- Mutaf M. and Temel M., Gunal E.: The reading man flap for closure of large meningomyelocele defects. J. Plast. Reconstr \& Aesthetic Surgery, 65: 578-583, 2012.

13- Luce E.A., Stigers S.W., Vandenbrink K.D., et al.: Splitthickness skin grafting of the myelomeningocele defect: A subset at risk for late ulceration. Plast. Reconstr. Surg., 87: 116-121, 1991.

14- Zide B.M.: Spina bifida. In: McCarthy J.G., editor. Plastic. surgery. Philadel. Phia: Saunders, p. 3780-90, 1990.

15- Taylor G.I. and Palmer J.H.: The vascular territories (angiosomes) of the body: Experimental study and clinical applications. Br. J. Plast. Surg., 40: 113, 1987.

16- Cologlu H., Ozcan B., Uysal A.C., Cologlu O. and Borman H.: Bilateral Propeller Flap Closure of Large Meningomyelocele Defects. Annal. Plast. Surg., 73 (1): 68-73, 2014.

17- Weerd L.D. and Weum S.:The butterfly design: Coverage of a large sacral defect with two pedicled lumbar artery perforator flaps. British Journal Plast. Surg., 55: 251-26, 2002.

18- Isik D., Teke L.S., Eseoglu M., Isik Y., Bilici S. and Atik B.: Closure of Large Myelomeningocele Defects Using Dorsal Intercostal Artery Perforator Flap. Annal. Plast. Surg., 67 (2): 159-163, 2011.

19- Bissell M.B., Greenspun D.T., Levine J., Rahal W., AlDhamin A., AlKhawaji A., et al.: The lumbar artery perforator flap: 3-dimensional anatomical study and clinical applications. Ann. Plast. Surg., 77: 469-76, 2016.

20- Tae S.P., Lim S.Y., Song J.K. and Joo H.S.: Dual Perforator Flap for Reconstruction of Large Sacral Defects: Superior Gluteal Artery Perforator Super-Flap with Parasacral Perforator. Arch. Reconstr. Microsurg., 26 (1): 14-17,2017.

21- Keles M.K., Demir A., Kucuker I., et al.: The effect of twisting on single and double based perforator flap viability: An experimental study in rats. Microsurgery, 2014 34 (6): 464-9, 2017. 